\title{
Same Wording, Distinct Concepts? Testing Differences Between Expectancies and Motives in a Mediation Model of Alcohol Outcomes
}

\author{
Emmanuel Kuntsche \\ Swiss Institute for the Prevention of Alcohol and Drug \\ Problems, Switzerland; Radboud University Nijmegen, \\ the Netherlands
}

\author{
Reinout W. Wiers and Tim Janssen \\ University of Amsterdam
}

\author{
Gerhard Gmel \\ Swiss Institute for the Prevention of Alcohol and Drug Problems, Switzerland; \\ Lausanne University Hospital, Switzerland
}

\begin{abstract}
Per definition, alcohol expectancies (after alcohol I expect X), and drinking motives (I drink to achieve X) are conceptually distinct constructs. Theorists have argued that motives mediate the association between expectancies and drinking outcomes. Yet, given the use of different instruments, do these constructs remain distinct when assessment items are matched? The present study tested to what extent motives mediated the link between expectancies and alcohol outcomes when identical items were used, first as expectancies and then as motives. A linear structural equation model was estimated based on a national representative sample of 5,779 alcohol-using students in Switzerland (mean age $=15.2$ years). The results showed that expectancies explained up to $38 \%$ of the variance in motives. Together with motives, they explained up to $48 \%$ of the variance in alcohol outcomes (volume, 5+ drinking, and problems). In 10 of 12 outcomes, there was a significant mediated effect that was often higher than the direct expectancy effect. For coping, the expectancy effect was close to zero, indicating the strongest form of mediation. In only one case (conformity and $5+$ drinking), there was a direct expectancy effect but no mediation. To conclude, the study demonstrates that motives are distinct from expectancies even when identical items are used. Motives are more proximally related to different alcohol outcomes, often mediating the effects of expectancies. Consequently, the effectiveness of interventions, particularly those aimed at coping drinkers, should be improved through a shift in focus from expectancies to drinking motives.
\end{abstract}

Keywords: drinking motives, alcohol expectancies, risky drinking, mediation, adolescents

According to the motivational model of alcohol use (Cox \& Klinger, 1988, 1990), the decision to drink or not is the result of several consecutive factors: historical circumstances (e.g., genetic disposition), personality characteristics (e.g., extraversion, sensation-seeking), sociocultural factors (e.g., drinking patterns), environmental factors (e.g., alcohol availability), situational and current factors (e.g., reinforcement from past drinking), alcohol expectancies, and drinking motives. Although the last two factors are

Emmanuel Kuntsche, Research Department, Swiss Institute for the Prevention of Alcohol and Drug Problems, Lausanne, Switzerland; Behavioural Science Institute, Radboud University Nijmegen, Nijmegen, the Netherlands; Reinout W. Wiers and Tim Janssen, Developmental Psychopathology, University of Amsterdam; Gerhard Gmel, Research Department, Swiss Institute for the Prevention of Alcohol and Drug Problems, Lausanne, Switzerland; Alcohol Treatment Center, Lausanne University Hospital, Lausanne, Switzerland.

Correspondence concerning this article should be addressed to Emmanuel Kuntsche, Swiss Institute for the Prevention of Alcohol and Drug Problems (SIPA), Research Department, P.O. Box 870, CH 1001 Lausanne, Switzerland. E-mail: ekuntsche@sfa-ispa.ch often considered as equivalent determinants of alcohol use and excessive drinking (see Baer, 2002; and Ham \& Hope, 2003, for reviews), both are conceptually different: "Expectancies are people's beliefs about what will happen if they (or other people) drink alcohol, whereas motives are the value placed on the particular effects they want to achieve, which motivate them to drink" (Cox \& Klinger, 2004 , p. 124). In other words, the expectation of a desired effect does not necessarily imply that a person decides to drink to achieve this effect simply because the corresponding expectancy is endorsed (Cooper, 1994). Of note, most research in this area has focused on expectancies and not on motives; that is, in the last 25 years, there were twice as many publications on alcohol expectancies than there were on drinking motives (Kuntsche, 2007). The present study attempts to disentangle empirically the effects of expectancies and motives.

Drinking motives can be classified according to two underlying dimensions that reflect the valence (positive or negative) on the one hand, and the source (internal or external) of the outcomes individuals expect to achieve by drinking on the other (Cooper, 1994; Kuntsche, Knibbe, Gmel, \& Engels, 2005). Thus, it is assumed that individuals 
drink to obtain positive outcomes (positive reinforcement) or to avoid negative consequences (negative reinforcement). They may also be motivated by internal rewards, such as enhancement of a desired internal emotional state, or by external rewards, such as social approval or acceptance. Crossing these two dimensions results in four different drinking motive categories: (a) internally generated, positive reinforcement motives (drinking to enhance positive mood), (b) externally generated, positive reinforcement motives (drinking to obtain social rewards), (c) internally generated, negative reinforcement motives (drinking to reduce negative emotions), and (d) externally generated, negative reinforcement motives (drinking to avoid social rejection).

The motivational model further assumes that, based on the sum of expectancies, each person has to make a conscious or unconscious decision (i.e., the motive) about whether he or she will consume alcohol in any given situation. Drinking motives are, therefore, the final step toward alcohol use, while alcohol expectancies influence drinking only insofar as they shape particular drinking motives. There is increasing evidence to support the hypothesis that drinking motives mediate the link between alcohol expectancies and different alcohol-related outcomes (i.e., frequency, quantity, 5+ drinking, and problems: Catanzaro \& Laurent, 2004; Cooper, Frone, Russell, \& Mudar, 1995; Cronin, 1997; Nagoshi, Nakata, Sasano, \& Wood, 1994; Read, Wood, Kahler, Maddock, \& Palfai, 2003). For example, a recent study observed a perfect mediation; that is, the previously strong link between expectancies and alcohol use was reduced to zero when drinking motives were taken into account (Kuntsche, Knibbe, Gmel, \& Engels, 2007), thus demonstrating the strongest form of mediation (Baron \& Kenny, 1986).

Unfortunately, despite increasing evidence, two problems persist. First, to the best of our knowledge, all previous studies on expectancy-motive associations chose only a select number of dimensions from the aforementioned valence/source classification. As a result, their findings may be biased because of the high correlation across motive dimensions (Kuntsche et al., 2005, for a review). For this reason, some authors argue that all four motive dimensions must be analyzed in a mutually adjusted way to determine the contribution of a specific motive dimension on alcohol use, drinking problems, and other variables (Kuntsche, Knibbe, Gmel, \& Engels, 2006). Second, all of these studies used slightly different items to measure expectancies and motives, which would imply that the effects of expectancies and those of motives are not strictly comparable.

This raises the question of the extent to which expectancies and motives can truly assess different underlying constructs if the exact same items are used but in two different formats (Wiers, 2008) - an expectancy format (after drinking alcohol I expect X) and a motive format (I drink to achieve $\mathrm{X}$ ). The present study will endeavor to answer this question. Based on a national representative sample, we estimated a comprehensive model (1) in which all four expectancy dimensions and all four motive dimensions of the valence/source classification were simultaneously taken into account, and (2) in which items were used to measure both expectancies and motives that differed only in terms of their wording, so as to represent the four expectancy dimensions and the four motive dimensions. Because expectancies are assumed to shape drinking motives, we posit that expectancies explain a significant part of the variance in drinking motives. Furthermore, drinking motives are hypothesized to explain a significant part of variance in alcohol-related outcomes (volume, risky drinking, and alcohol-related problems). Finally, we expect the link between expectancies and alcohol outcomes to be mediated through motives.

\section{Method}

\section{Study Design}

The data stem from the Swiss participation in the "European School Survey Project on Alcohol and Drugs" (ESPAD; www.espad.org). The survey used a stratified sample in which classes were randomly selected proportionate to canton size (Swiss counties). Once permission to conduct the survey was obtained from the Ethical Committee for Clinical Research at Lausanne University (protocol no. 119/07) and from the relevant cantonal education authorities, principals of the selected schools were informed. Self-completion questionnaires were administered in class between April and June 2007. Participants could freely choose to participate and confidentiality was ensured at all stages of the study. More information about the ESPAD study in Switzerland can be found, for example, in Kuntsche et al. (2006); Kuntsche et al. (2007), and Kuntsche, Knibbe, Engels and Gmel (2010).

\section{Measures}

Alcohol expectancies and drinking motives. The Drinking Motive Questionnaire-Revised (DMQ-R; Cooper, 1994), the most widely used instrument to assess drinking motives among young people (for a review, see Kuntsche et al., 2005), has been added to the standard ESPAD core questionnaire. The latter contained by default a battery of alcohol outcome expectancies, of which five items already matched the items of the DMQ-R. Based on their psychometric properties (size of factor loadings, etc.) identified in a previous study (Kuntsche et al., 2006), we added further motive items to the existing ESPAD expectancy battery. Because of the given timeframe of one school lesson (about $45 \mathrm{~min}$ ) to fill in the questionnaires, we could include only the following three matching motive-expectancy item pairs in each dimension: social ("to be sociable," "to better enjoy a party," "to celebrate special occasions with friends"); enhancement ("to have a lot of fun," "because it gives a pleasant feeling," "to get high"); coping ("to forget about problems," "to feel less depressed or nervous," "to cheer up when in a bad mood"); and conformity ("to be liked," "to fit in with a group," "not to feel left out"). Although the items to measure both expectancies and motives were almost identical, the question that introduced the items and the answer categories differed. "How likely is it 
that each of the following things would happen to you personally if you drink alcohol?" was the question for expectancies, and the answer categories were "very unlikely," "unlikely," "unsure," "likely," and "very likely." For motives, the question was "Think about all the occasions that you have consumed alcohol (beer, wine, liquor, mixed drinks, etc.) over the past 12 months. How often have you drunk alcohol for the following reasons?", with the answer categories "never," "rarely," "sometimes," "often," "usually," and "almost always." To minimize complexity and the number of parameters to be estimated in the comprehensive model displayed in Figure 1, the three items in each expectancy and motive dimension were added to produce a summary score.

Drinking volume $(\mathbf{Q F})$. The total number of drinks consumed in the last 12 months was obtained by multiplying the number of standard drinks of any alcoholic beverage (e.g., beer, wine, spirits, and alcopops) consumed at a typical occasion (Quantity) by the number of drinking occa- sions in the last 12 months (Frequency). For example, students who indicated 10 drinking occasions in the last 12 months and an average of two drinks at typical occasions scored 20 drinks on the drinking volume measure. Frequency answer categories ranged from 1 to 40 or more. To create a linear measure, midpoints of categories were used, with 45 occasions used for the upper category (40 times plus half range to midpoint of adjacent category). The usual quantity answer categories ranged from "less than 1 drink" to " 5 or more drinks." Midpoints of categories were used, with 0.5 drinks for the lowest category and 5.5 drinks for the highest.

5+ drinking. According to the Wechsler definition (Wechsler \& Nelson, 2001), the question was "Think back again over the last 30 days. How many times (if any) have you had five or more drinks on one occasion?" with the answer categories "none," "1," "2," "3-5," "6-9," and "10 or more times." Midpoints of categories were used, with 11.25 occasions used for the upper category (10 times plus half range to midpoint of the adjacent category).

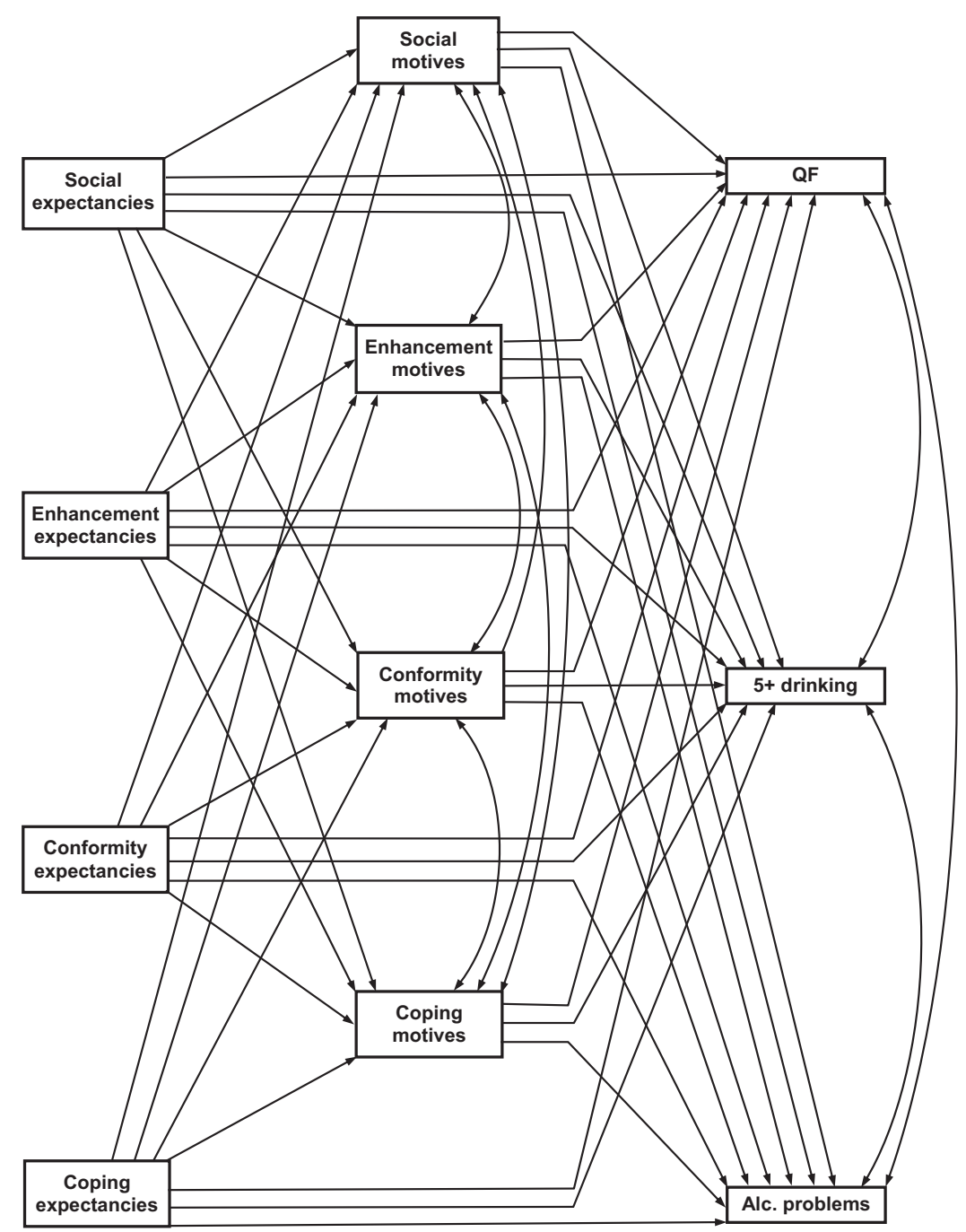

Figure 1. Estimated regression model. 
Alcohol-related problems. Participants were asked: "Because of your own alcohol use, how often during the last 12 months have you experienced the following?" Four types of problems were included: academic ("poor performance at school or work"), violence ("physical fight"), injury ("accident or injury"), and sex-related ("engaged in sexual intercourse that was regretted the next day"). Response categories ranged from never to 40 or more. Midpoints of categories were used, with 45 occasions used for the upper category (40 times plus half range to midpoint of the adjacent category). The internal consistency of the four items was Cronbach's alpha = .80. For the analysis, the items were added up to produce a summary score ranging from 0 to 180 .

\section{Sample and Missing Value Imputation}

Random cluster sampling was used, based on a list of all 8th to 10th grade classes in public schools with the classes serving as the primary sampling unit. Eighty-eight percent of questionnaires were sent back within the required time limit of three months. Only $5.8 \%$ of the students in the participating classes did not complete the survey because they were absent, because of illness or truancy, or because they simply refused to take part. This resulted in an overall response rate of $82.8 \%$. The final sample of 7,623 adolescents can be considered as representative for all 8th, 9th, and 10th graders in public schools in the three main linguistic regions (German, French, and Italian) of Switzerland. Because drinking motives were exclusively assessed among drinkers, those who did not indicate at least one drinking occasion in the last 12 months $(n=1,584,20.8 \%)$ were excluded.

All students who failed to answer five or more questions on drinking motives and alcohol expectancies $(n=169$; $2.8 \%$ ) were excluded from the analysis. Students who did not answer all of the questions on alcohol use were excluded from the analysis $(n=91 ; 1.5 \%)$. The analyzed data consist of 5,779, 13- to 19-year old alcohol-using students $(40.6 \%$ 8th graders, $46.0 \%$ 9th graders, and $13.4 \%$ 10th graders), of which $49.0 \%$ were boys; $70.9 \%$ of them came from German-speaking Switzerland (29.1\% from the French- or Italian-speaking part). The mean age of the total sample was 15.4 years $(S D=1.0) ; 21.3 \%$ in the final sample were 16 years and older (i.e., the legal purchase age for nondistilled alcoholic beverages in Switzerland).

Remaining missing values per item were generally below $1 \%$. However, because 33 items were used in the present study, 796 participants $(13.3 \%)$ had left at least one of them (and up to four at maximum) unanswered. These missing values were replaced by means of Markov Chain Monte Carlo estimates (Gilks, Richardson, \& Spiegelhalter, 1996). The advantage of this imputation method is that it takes into account the information on observed values for an individual; imputation is conditional on individuals that have the same response pattern on all but the missing items. Thus, a maximum of information for each individual item in the expectancy or motive questionnaire was used. The
LISREL 8.51 program (Jöreskog \& Sörbom, 2001) calculated the missing value imputations.

\section{Statistical Analysis}

Figure 1 shows the estimated regression model. Adjusted for gender and age effects, the model was estimated using Mplus 5.1 software (Muthén \& Muthén, 2007). The most widely used method to assess mediation is the classic Baron and Kenny (1986) causal steps approach. Here, the difference between the effect in the bivariate predictor-outcome link (c) and the effect of the same link but including the mediator (c') provides evidence of mediation. The demonstration of the algebraic equivalence of the effect difference $c-c^{\prime}$ and the product $\left(a^{*} b\right)$ of the effect in the predictormediator link (a) with the effect of the mediator-outcome link (b) made it possible to test mediation in a single-step model (for a discussion, see MacKinnon, Fairchild, \& Fritz, 2007). Accordingly, in the present study, the size and significance level of the product of the coefficient of the paths between expectancies and motives (a) and the paths between motives and alcohol outcomes (b) which are directly provided in Mplus, provides evidence of mediation. The rationale behind this procedure is that mediation depends on the extent to which the independent variables affect the mediators (i.e., paths from expectancies to motives), and the extent to which the mediators affect the outcome variables (i.e., paths from motives to alcohol outcomes). If c' is significant besides the significant mediation $\left(a^{*} b\right)$ there is evidence for partial mediation (MacKinnon et al., 2007). The strongest form of mediation occurs when c' is nonsignificant and its effect zero or close to zero (Baron \& Kenny, 1986). The delta method was used to obtain standard errors and the significance levels of the mediated effects (Muthén \& Muthén, 2007). To address the question of reversed causation, we also estimated a model in which expectancies were included as mediators in the link between motives and three alcohol outcomes (cf. Cronin, 1997). The results of this "inverse mediation" were subsequently compared with the results obtained in the original mediation model described earlier.

The intraclass correlations (ICC) of the alcohol outcome variables because of the sampling of school classes instead of individuals were $\mathrm{ICC}_{\mathrm{QF}}=.14, \mathrm{ICC}_{5+}=.08$, and $\mathrm{ICC}_{\text {Problems }}=.05$. Sandwich estimated robust standard errors were used to account for the cluster sampling design effect and the non-normal distribution of outcomes. In addition, each of the three alcohol outcome variables was log-transformed to approximate a normal distribution and to reduce the impact of extreme values (Tabachnick \& Fidell, 2001). To test the robustness of the results and the accuracy of the standard errors of the mediated effects (MacKinnon et al., 2007), the model was then reestimated by means of bootstrap resampling for which 500 random draws were taken.

Reported effect sizes are standardized regression coefficients (Betas) and explained variance $\left(R^{2}\right)$. Because of the multiple outcomes in the present study (e.g., 4 dimensions $* 3$ alcohol measures), the $\alpha$-error threshold was Bon- 
ferroni corrected (e.g., $\alpha^{\prime}=\alpha / 12$ ). This more conservative error level also attenuates the fact that low effect sizes are reported as statistically significant because of the high sample size of nearly 6,000 participants. To evaluate the overall model fit, we used the comparative fit index (CFI) and the standardized mean square residual (SRMR). The CFI relates to the total variance accounted for by the model, where values close to 1 , that is, higher than .90, were sought (Kline, 2005). The SRMR relates to the residual variance, where values close to 0 , that is, lower than .10, were sought (Kline, 2005).

\section{Results}

Descriptive results reveal that 13- to 19-year old participants had consumed an average of 37.7 drinks in the last 12 months $(S D=59.9)$. In the last 30 days, 2,053 students $(35.5 \%)$ indicated that they had consumed five or more drinks in a row on at least one occasion. The sample average was 0.95 occasions $(S D=2.0)$. In the last 12 months, 1,239 students had experienced academic, violence, injury, or sex-related problems because of their alcohol consumption; the sample average was $1.59(S D=9.4)$.

Regarding cognitive motivational factors, participants scored highest on enhancement expectancies and motives, and lowest on conformity expectancies and motives (see Table 1). Of note, while participants scored equally high on social and coping expectancies, they scored higher on social than on coping motives $\left(\Delta_{\text {mean }}=-.63, t=-44.8, p<\right.$ $.001)$. Each expectancy and motive dimension had a satisfactory-to-good internal consistency (note that alpha values of at least .7 are considered as satisfactory, Nunnally \& Bernstein, 1994). The only exception was enhancement expectancies where the internal consistency was slightly lower than the required .7 threshold. Consistently, the internal consistencies were slightly higher for motives than for expectancies.

In all cases, the best predictor for a particular motive dimension was the corresponding expectancy dimension (social-social, enhancement-enhancement, etc.), where the effect sizes (between $\beta=.30$ and $\beta=.48$ ) were quite high. In addition, social expectancies were related to enhancement motives ( $\beta=.27$ ) and enhancement expectancies to social motives $(\beta=.19)$. Taken together, alcohol expectancies explained $10 \%$ to $34 \%$ of the variance in drinking motives. The model fit, $\chi^{2}(d f=8)=326.8$; CFI $=.981$; SRMR $=.022$, was good (Kline, 2005).

For the enhancement dimension (all outcomes) and for the social and conformity dimension (only QF), there was a significant link for expectancies, motives, and the mediated relationship (Table 2). For example, the original bivariate effect of social expectancies on $\mathrm{QF}^{1}$ was $\beta=.16$ when social motives were not included (cf. also Appendix). It is then split into a reduced direct expectancy effect (c') of $\beta=$ $.08)$ and a mediated effect via motives $\left(a^{*} \mathrm{~b}\right)$ of $\beta=.08$. For the coping dimension (all outcomes) and for the social (only $5+$ drinking) and conformity (only alcohol-related problems) dimensions, there was a significant link for motives and for the mediation effect but not for expectancies. For the social dimension and alcohol-related problems, no significant link was found at all, while for the conformity dimension and $5+$ drinking, only expectancies were significantly related. The significant links of the conformity dimension to the two alcohol use measures were negative, yet they were positive for alcohol-related problems.

When expectancies were treated as mediators in the motive-alcohol outcome link, the direct effects of expectancies and motives remained basically the same. ${ }^{1}$ However, the mediation effects were much weaker and often failed to be significant despite the large sample size. This was particularly the case for the enhancement and coping dimensions (all outcomes) and alcohol problems (all dimensions), where the original mediation effect via motives was at least three times as high as the inverse mediation effect (i.e., when expectancies were taken as mediators). The only exception was the conformity dimension with the number of consumed drinks: the effect of the inverse mediation was slightly higher here than that of the original mediation.

Nearly half of the variance in QF was explained by expectancies and motives. These explained about one third of the variance for $5+$ drinking, and nearly one quarter of the variance in alcohol-related problems. Reestimation of the model by means of bootstrap resampling showed that the results ${ }^{2}$ were very similar to those reported in Table 2. This underscores the robustness and accuracy of the reported findings.

\section{Discussion}

The aim of the present study was to test the mediation of drinking motives in the link between expectancies and alcohol outcomes by means of a comprehensive model (1) in which all four expectancy dimensions and all four motive dimensions from the valence/source classification were simultaneously taken into account, and (2) in which similar item formulations were used to measure the expectancy dimensions and the motive dimensions separately.

The main results can be summarized as follows. First, when formulated as similarly as possible, expectancies and motives remain separate constructs. Consistent with previous research, participants scored highest on positive reinforcement motives (enhancement and social) followed by coping and conformity motives, in that order (see Kuntsche et al., 2005; Kuntsche, Stewart, \& Cooper, 2008, for overviews). However, no such difference was found for social and coping expectancies (Kuntsche, Knibbe, Gmel, et al., 2007), for example.

Second, motives mediated the link between expectancies and alcohol outcomes. In 10 out of 12 outcomes, there was a significant mediation effect, which was often higher than the corresponding direct expectancy effect. In only one case (i.e., conformity and 5+ drinking), there was a direct expectancy effect but no mediation. However, the effect size was rather low. For coping (all three outcomes) and con-

\footnotetext{
${ }^{1}$ That is, $c=c^{\prime}+a^{*} b$, not reported in the tables.

${ }^{2}$ Available upon request from the first author.
} 
Table 1

Alcohol Expectancies as Predictors of Drinking Motives (Standardized Betas, T-Values in Brackets, and Explained Variance) and Internal Consistencies and Means (SDs in Brackets)

\begin{tabular}{|c|c|c|c|c|c|c|}
\hline \multirow[b]{2}{*}{ Alcohol expectancies } & \multicolumn{4}{|c|}{ Drinking motives } & \multirow[b]{2}{*}{ Cronbach's $\alpha$} & \multirow[b]{2}{*}{$M(S D)$} \\
\hline & Social & Enhancement & Coping & Conformity & & \\
\hline Social & $.48^{* * * *}(29.3)$ & $.27^{* * * *}(16.8)$ & $.09^{* * * *}(4.9)$ & $.04(2.4)$ & .719 & $3.30(1.0)$ \\
\hline Enhancement & $.19^{* * * * *}(11.8)$ & $.45^{* * * * *}(30.6)$ & $.13^{* * * * *}(7.5)$ & $.01(0.5)$ & .619 & $3.60(0.9)$ \\
\hline Coping & $-.01(-0.6)$ & $.03(1.7)$ & $.32^{* * * *}(17.6)$ & $-.03(-1.7)$ & .695 & $3.30(0.9)$ \\
\hline Conformity & $-.07^{* * * * *}(-5.2)$ & $-.16^{* * * *}(-12.5)$ & $-.07^{* *}(-4.0)$ & $.30^{* * * *}(20.0)$ & .742 & $2.53(1.0)$ \\
\hline$R^{2}$ & $33.6 \%$ & $37.8 \%$ & $19.7 \%$ & $10.0 \%$ & & \\
\hline$M(S D)$ & $2.38(1.2)$ & $2.49(1.4)$ & $1.75(1.1)$ & $1.20(0.6)$ & & \\
\hline Cronbach's $\alpha$ & .733 & .842 & .849 & .822 & & \\
\hline
\end{tabular}

Note. Bonferoni-corrected $\alpha$-error thresholds: range of expectancy response categories: strongly disagree (coded as 1) to strongly agree (coded as 5); range of motive response categories: never (coded as 1) to almost always (coded as 6).

*** $p<.01 / 16$. ${ }_{* * * *} p<.001 / 16$.

formity (only alcohol-related problems), the direct expectancy effect was zero or close to zero, thus demonstrating the strongest form of mediation (Baron \& Kenny, 1986). Moreover, when taking expectancies as mediators in the motivealcohol outcome link, much weaker mediation effects were found which often failed to be significant despite the high sample size. These results are consistent with previous evidence (Catanzaro \& Laurent, 2004; Cooper et al., 1995; Cronin, 1997; Kuntsche, Knibbe, Gmel, et al., 2007; Nagoshi et al., 1994; Read et al., 2003) and support the assumption of the motivational model of alcohol use (Cox \& Klinger, 1988, 1990) that drinking motives are the final decision toward alcohol use, that is, the gateway through which more distal influences, such as alcohol expectancies, are mediated.
However, not all expectancy effects were entirely mediated by motives. In case of enhancement (both drinking measures) and social and conformity (only QF), there was only partial mediation, that is, both the direct expectancy effect and the mediated effect through motives were significant. How is it possible that the likelihood of expected effects explains the variance in drinking over and above the personal decision (i.e., motivation) to consume alcohol? One explanation is that having a particular expectancy does not automatically mean that an individual consciously decides to drink to achieve the desired effect (Cooper, 1994). For example, adolescents infrequently might decide (consciously) to drink with the intention of getting drunk and having fun. However, regardless of their motivation, those who strongly expect such outcomes (without necessarily

Table 2

Alcohol Expectancies and Drinking Motives as Simultaneous Predictors of Alcohol Use in Multiple-Multivariate Regression Models (Standardized Betas, T-Values in Brackets)

\begin{tabular}{|c|c|c|c|}
\hline & Drinking volume $(\mathrm{QF})$ & $5+$ drinking & Alcohol problems \\
\hline \multicolumn{4}{|l|}{ Social } \\
\hline Expectancy effect (c') & $.08^{* * * *}(4.6)$ & $.04(2.4)$ & $-.01(-0.3)$ \\
\hline Motive effect (b) & $.17^{* * * * *}(11.2)$ & $.06^{*}(2.9)$ & $.03(1.4)$ \\
\hline Mediated effect (a*b) & $.08^{* * * *}(10.7)$ & $.03 *(2.9)$ & $.01(1.4)$ \\
\hline Inverse mediation & $.03^{* * *}(4.5)$ & $.02(2.4)$ & $-.00(-0.3)$ \\
\hline \multicolumn{4}{|l|}{ Enhancement } \\
\hline Expectancy effect (c') & $.12^{* * * *}(7.8)$ & $.11^{* * * *}(6.7)$ & $.05(2.5)$ \\
\hline Motive effect (b) & $.36^{* * *}(22.6)$ & $.34^{* * * *}(19.0)$ & $.20^{* * * * *}(9.1)$ \\
\hline Mediated effect $\left(a^{*} b\right)$ & $.16^{* * *}(18.2)$ & $.15^{* * * *}(15.9)$ & $.09^{* * * *}(8.7)$ \\
\hline Inverse mediation & $.05^{* * *}(7.5)$ & $.05^{* * *}(6.6)$ & $.02(2.5)$ \\
\hline \multicolumn{4}{|l|}{ Coping } \\
\hline Expectancy effect (c') & $-.01(-0.3)$ & $-.03(-2.0)$ & $-.01(-0.6)$ \\
\hline Motive effect (b) & $.11^{* * * *}(8.2)$ & $.16^{* * * * *}(8.5)$ & $.25^{\text {*** }}(12.3)$ \\
\hline Mediated effect $\left(a^{*} b\right)$ & $.03^{* * * *}(7.3)$ & $.05^{* * * *}(7.7)$ & $.08^{* * *}(9.9)$ \\
\hline Inverse mediation & $-.00(-0.3)$ & $-.01(-2.8)$ & $-.00(-0.7)$ \\
\hline \multicolumn{4}{|l|}{ Conformity } \\
\hline Expectancy effect (c') & $-.11^{* * * *}(-8.3)$ & $-.04^{*}(-2.9)$ & $-.01(-0.4)$ \\
\hline Motive effect (b) & $-.05^{* * * *}(-4.2)$ & $-.00(-0.1)$ & $.11^{* *}(3.7)$ \\
\hline Mediated effect $\left(a^{*} b\right)$ & $-.02^{\text {**** }}(-4.1)$ & $.00(-0.1)$ & $.03^{* *}(3.6)$ \\
\hline Inverse mediation & $-.03^{* * * *}(-7.1)$ & $-.01(-2.0)$ & $-.00(-0.4)$ \\
\hline$R^{2}$ & $48.2 \%$ & $33.7 \%$ & $24.2 \%$ \\
\hline
\end{tabular}

Note. All models were adjusted for gender and age; inverse mediation: effect of motives mediating the link between expectancies and alcohol outcomes; Bonferoni-corrected $\alpha$-error thresholds. ${ }^{*} p<.05 / 12 .{ }^{* * *} p<.01 / 12 .{ }^{* * * *} p<.001 / 12$. 
making a conscious decision or originally intending to do so) seem to drink higher volumes and to be more frequently intoxicated than those who do not have this expectancy. To some degree, this also applies to drinking to improve social gatherings, which might, in some cases, be directly related to the underlying associations (Moss \& Albery, 2009; Wiers $\&$ Stacy, 2010). To the extent that expectancies are based on a single simple association (e.g., alcohol = fun), expectancies may be primed without awareness (Moss \& Albery, 2009; Wiers \& Stacy, 2010). However, other expectancies require a propositional structure over and above single associations (Wiers, Houben, Smulders, Conrod, \& Jones, 2006). In line with this reasoning, the present study found that alcohol consumption appears to be more explicit and intended for coping drinkers, that is, to forget about problems or to feel less depressed, and is fully mediated by motives. Without deciding to drink, the expectancy alone does not appear to help achieve the desired effect (easing worries). Consequently, a complete mediation was found.

Expectancies were also important in the negative link between conformity expectancies and the two drinking measures. Conformity motives are usually indicated by adolescents who drink rarely, that is, on special occasions, such as family celebrations, weddings, New Year's Eve, so as to fit in with a group and not to feel left out. In such cases, only one drink is usually enough to fulfill this function, that is, getting drunk might be even counterproductive to their aim of fitting in and not feeling left out. Consequently, their decision (motivation) to engage in drinking seems to be less important for their infrequent and low-quantity drinking than the expectancies that they are likely to be socially accepted if they drink (which they rarely do in reality). Besides the importance of conformity expectancies for the negative link to drinking, conformity motives and mediation were positively associated with the number of alcoholrelated problems in the last 12 months. This contradictory result, which is consistent with previous research (Cooper, 1994; Kuntsche, Knibbe, Engels, \& Gmel, 2007), might be explained by the existence of two distinct groups (Kuntsche, 2007). Besides the majority of conformity drinkers mentioned above who consume infrequently and in small quantities per occasion, there appears to be another relatively small group of conformity drinkers who have deviant peers and multiple alcohol-related problems. In such peer groups, alcohol use is likely to be perceived as the group norm (e.g., Kuntsche \& Gmel, 2004; Rossow, Pape, \& Wichstrøm, 1999). Also, drinking to fit into the group and to avoid peer rejection (i.e., conformity motives) appears to play a particularly important role (Kuntsche, 2007).

Although the study yielded important results, a number of limitations should be acknowledged. First, expectancies and motives were deliberately made equivalent, beginning with motives. As a consequence, it could be argued that some of the more specific expectancies (e.g., sexual enhancement) were not included in the measurement, and this may have favored motives. Similarly, negative expectancies and the related concept of reasons for abstaining were not included. Hence, the study could be repeated with a fuller range of expectancies and motives. Second, the study was cross- sectional, and it is possible that expectancies predict unique variance which is not mediated by motives in a prospective analysis. Using longitudinal designs, it would be important to confirm empirically the assumed causal chain of alcohol expectancies in late childhood and even before the establishment of drinking habits which lead to drinking motives in early adolescence, which in turn lead to alcohol use and excessive drinking, and ultimately to alcohol-related problems in later life. Third, the sample consisted exclusively of adolescents, a relatively inexperienced group on average when it comes to alcohol consumption. It is possible that expectancies and motives may blend together more among older individuals who have a longer drinking career. Among the strengths of the study is the national representative sample of nearly 6,000 alcohol-using students. This large sample enabled the estimation of a comprehensive model in which similar item formulations were used to measure both the expectancy dimensions and the motive dimensions.

The present results also have major implications for prevention. It appears, for example, that expectancy challenge interventions (e.g., Darkes \& Goldman, 1998) may be more appropriate for social and enhancement drinkers and less effective for coping drinkers. The fact that these challenges are often applied universally to students and not according to their drinking motives might be the reason why these programs have demonstrated limited efficacy so far (e.g., van de Luitgaarden, Wiers, Knibbe, \& Candel, 2007; Wiers \& Kummeling, 2004; Wiers, van de Luitgaarden, van den Wildenberg, \& Smulders, 2005; Wood, Capone, Laforge, Erickson, \& Brand, 2007). For coping drinkers, it may be more effective to intervene at the level of drinking motives and related factors. For example, an approach to prevent early and risky drinking among adolescents has been developed recently based on the assumption that by intervening at the level of personality, it is possible to change or to help manage adolescents' maladaptive drinking motives (e.g., coping and enhancement), and ultimately to reduce excessive drinking and alcohol-related problems (Conrod, Stewart, Comeau, \& Maclean, 2006).

From a developmental point of view, drinking motives are particularly important among adolescents who have already established certain drinking patterns. Among those who have yet to start drinking or who drink infrequently like conformity drinkers, alcohol expectancies may be more important factors and thus merit inclusion in prevention programs. However, the possibility of iatrogenic effects of such an approach should be borne in mind (Wiers, Sergeant, \& Gunning, 2000). In addition, alcohol expectancies appear to be promising in terms of primary prevention, for example, the reduction of positive alcohol expectancies that adolescents might have and to reinforce their negative expectancies before engaging in alcohol use for the first time (Kuntsche, Knibbe, Gmel, et al., 2007). Drinking motives appear to offer promising potential for secondary prevention, for example, the reduction of those coping motives which have been shown to be related to problematic alcohol use and alcohol-related problems (see Kuntsche et al., 2005, for a review). Certain authors argue that the identification and collection of information on the specific needs that 
alcohol serves for particular individuals via drinking motives could lead to the creation of more effective prevention strategies (Cooper, 1994; Kuntsche et al., 2010).

In conclusion, even when the wording of expectancies and motives match, they still assess distinct yet related constructs, with motives mediating the relationship between expectancies and drinking outcomes. The study found that this was the case for almost all the dimensions (social, enhancement, coping, conformity), as well as for the various alcohol outcome measures.

\section{References}

Baer, J. S. (2002). Student factors: Understanding individual variation in college drinking. Journal of Studies on Alcohol, 14(Suppl.), 40-53.

Baron, R. M., \& Kenny, D. A. (1986). The moderator-mediator variable distinction in social psychological research: Conceptual, strategic, and statistical considerations. Journal of Personality and Social Psychology, 51, 1173-1182.

Catanzaro, S. J., \& Laurent, J. (2004). Perceived family support, negative mood regulation expectancies, coping, and adolescent alcohol use: Evidence of mediation and moderation effects. Addictive Behaviors, 29, 1779-1797.

Conrod, P. J., Stewart, S. H., Comeau, N., \& Maclean, A. M. (2006). Efficacy of cognitive behavioral interventions targeting personality risk factors for youth alcohol misuse. Journal of Clinical Child and Adolescent Psychology, 35, 550-563.

Cooper, M. L. (1994). Motivations for alcohol use among adolescents: Development and validation of a four-factor-model. Psychological Assessment, 6, 117-128.

Cooper, M. L., Frone, M. R., Russell, M. A., \& Mudar, P. (1995). Drinking to regulate positive and negative emotions: A motivational model of alcohol use. Journal of Personality and Social Psychology, 69, 990-1005.

Cox, W. M., \& Klinger, E. (1988). A motivational model of alcohol use. Journal of Abnormal Psychology, 97, 168-180.

Cox, W. M., \& Klinger, E. (1990). Incentive motivation, affective change, and alcohol use: A model. In W. M. Cox (Ed.), Why people drink: Parameters of alcohol as a reinforcer (pp. 291314). New York: Gardner Press, Inc.

Cox, W. M., \& Klinger, E. (2004). A motivational model of alcohol use: Determinants of use and change. In W. M. Cox \& E. Klinger (Eds.), Handbook of motivational counseling: Concepts, approaches, and assessment (pp. 121-138). Chichester: Wiley, Ltd.

Cronin, C. (1997). Reasons for drinking versus outcome expectancies in the prediction of college student drinking. Substance Use and Misuse, 32, 1287-1311.

Darkes, J., \& Goldman, M. S. (1998). Expectancy challenge and drinking reduction: Process and structure in the alcohol expectancy network. Experimental and Clinical Psychopharmacology, 6, 64-76.

Gilks, W. R., Richardson, S., \& Spiegelhalter, D. J. (Eds.). (1996). Markov Chain Monte Carlo in practice: Interdisciplinary statistics. London: Chapman \& Hall.

Ham, L. S., \& Hope, D. A. (2003). College students and problematic drinking: A review of the literature. Clinical Psychology Review, 23, 719-759.

Jöreskog, K. G., \& Sörbom, D. (2001). LISREL Software Version 8.51. Chicago: Scientific Software International, Inc.

Kline, R. B. (Ed.). (2005). Principles and practice of structural equation modeling (2nd ed.). New York: The Guilford Press.

Kuntsche, E. (2007). Tell me ... Why do you drink? A study of drinking motives in adolescence. Lausanne, Switzerland: SIPA-Press.
Kuntsche, E., \& Gmel, G. (2004). Emotional well-being and violence among social and solitary risky single occasion drinkers in adolescence. Addiction, 99, 331-339.

Kuntsche, E., Knibbe, R., Engels, R., \& Gmel, G. (2007). Bullying and fighting among adolescents: Do drinking motives and alcohol use matter? Addictive Behaviors, 32, 3131-3135.

Kuntsche, E., Knibbe, R., Engels, R. C. M. E., \& Gmel, G. (2010). Identifying enhancement and coping drinkers among risky drinking adolescents. European Journal of Psychological Assessment, 26, 46-54

Kuntsche, E., Knibbe, R., Gmel, G., \& Engels, R. (2005). Why do young people drink? A review of drinking motives. Clinical Psychology Review, 25, 841-861.

Kuntsche, E., Knibbe, R., Gmel, G., \& Engels, R. (2006). Replication and validation of the Drinking Motive Questionnaire Revised (DMQ-R, Cooper, 1994) among adolescents in Switzerland. European Addiction Research, 12, 161-168.

Kuntsche, E., Knibbe, R., Gmel, G., \& Engels, R. (2007). Drinking motives as mediators of the link between alcohol expectancies and alcohol use among adolescents. Journal of Studies on Alcohol and Drugs, 68, 76-85.

Kuntsche, E., Stewart, S. H., \& Cooper, M. L. (2008). How stable is the motive-alcohol use link? A cross-national validation of the Drinking Motive Questionnaire Revised among adolescents from Switzerland, Canada, and the United States. Journal of Studies on Alcohol and Drugs, 69, 388-396.

MacKinnon, D. P., Fairchild, A. J., \& Fritz, M. S. (2007). Mediation analysis. Annual Review of Psychology, 58, 593-614.

Moss, A. C., \& Albery, I. P. (2009). A dual-process model of the alcohol-behavior link for social drinking. Psychological Bulletin, 135, 516-530.

Muthén, L. K., \& Muthén, B. O. (2007). Mplus: User's guide (5th ed.). Los Angeles: Muthén \& Muthén.

Nagoshi, C. T., Nakata, T., Sasano, K., \& Wood, M. D. (1994). Alcohol norms, expectancies, and reasons for drinking and alcohol use in a U.S. versus a Japanese college sample. Alcoholism: Clinical and Experimental Research, 18, 671-678.

Nunnally, J. C., \& Bernstein, I. (1994). Psychometric theory (3rd ed.). New York: McGraw-Hill

Read, J. P., Wood, M. D., Kahler, C. W., Maddock, J. E., \& Palfai, T. P. (2003). Examining the role of drinking motives in college student alcohol use and problems. Psychology of Addictive Behaviors, 17, 13-23.

Rossow, I., Pape, H., \& Wichstrøm, L. (1999). Young, wet \& wild? Associations between alcohol intoxication and violent behaviour in adolescence. Addiction, 94, 1017-1031.

Tabachnick, B. G., \& Fidell, L. S. (2001). Using multivariate statistics (4th ed.). Boston: Allyn \& Bacon.

van de Luitgaarden, J., Wiers, R. W., Knibbe, R. A., \& Candel, M. J. J. M. (2007). Single-session expectancy challenge with young heavy drinkers on holiday. Addictive Behaviors, 32, 2865-2878.

Wechsler, H., \& Nelson, T. F. (2001). Binge drinking and the American college student: What's five drinks? Psychology of Addictive Behaviors, 15, 287-291.

Wiers, R. W. (2008). Alcohol and drug expectancies as anticipated changes in affect: Negative reinforcement is not sedation. Substance Use and Misuse, 43, 429-444.

Wiers, R. W., Houben, K., Smulders, F. T. Y., Conrod, P. J., \& Jones, B. T. (2006). To drink or not to drink: The role of automatic and controlled cognitive processes in the etiology of alcohol-related problems. In R. W. Wiers \& A. W. Stacy (Eds.), Handbook of implicit cognition and addiction (pp. 339-361). Thousand Oaks, CA: Sage. 
Wiers, R. W., \& Kummeling, R. H. C. (2004). An experimental test of an alcohol expectancy challenge in mixed gender groups of young heavy drinkers. Addictive Behaviors, 29, 215-220.

Wiers, R. W., Sergeant, J. A., \& Gunning, W. B. (2000). The assessment of alcohol expectancies in school children: Measurement or modification? Addiction, 95, 737-746.

Wiers, R. W., \& Stacy, A. W. (2010). Are alcohol expectancies associations? Comment on Moss and Albery (2009). Psychological Bulletin, 136, 12-16.
Wiers, R. W., van de Luitgaarden, J., van den Wildenberg, E., \& Smulders, F. T. Y. (2005). Challenging implicit and explicit alcohol-related cognitions in young heavy drinkers. Addiction, 100, 806-819.

Wood, M. D., Capone, C., Laforge, R., Erickson, D. J., \& Brand, N. H. (2007). Brief motivational intervention and alcohol expectancy challenge with heavy drinking college students: A randomized factorial study. Addictive Behaviors, 32, 25092528 .

\section{Appendix}

\section{Correlation Matrix of Demographic Variables, Alcohol Expectancies, Drinking Motives, and Alcohol Outcomes}

\begin{tabular}{|c|c|c|c|c|c|c|c|c|c|c|c|c|}
\hline & 1 & 2 & 3 & 4 & 5 & 6 & 7 & 8 & 9 & 10 & 11 & 12 \\
\hline 2. Age & .01 & & & & & & & & & & & \\
\hline 3. Social expectancies & .12 & .07 & & & & & & & & & & \\
\hline 4. Enhancement expectancies & .08 & .08 & .66 & & & & & & & & & \\
\hline 5. Coping expectancies & .02 & -.02 & .63 & .63 & & & & & & & & \\
\hline 6. Conformity expectancies & .04 & -.08 & .49 & .37 & .49 & & & & & & & \\
\hline 7. Social motives & .09 & .19 & .56 & .47 & .38 & .22 & & & & & & \\
\hline 8. Enhancement motives & .12 & .16 & .50 & .58 & .40 & .15 & .67 & & & & & \\
\hline 9. Coping motives & -.08 & .06 & .34 & .36 & .42 & .18 & .52 & .48 & & & & \\
\hline 10. Conformity motives & .05 & .00 & .18 & .13 & .15 & .31 & .33 & .23 & .32 & & & \\
\hline 11. Drinking volume (QF) & .14 & .30 & .41 & .45 & .30 & .05 & .56 & .63 & .40 & .12 & & \\
\hline 12. $5+$ drinking & .14 & .18 & .34 & .39 & .26 & .09 & .45 & .54 & .38 & .15 & .62 & \\
\hline 13. Alcohol-related problems & .11 & .11 & .25 & .28 & .22 & .12 & .36 & .40 & .40 & .25 & .39 & .46 \\
\hline
\end{tabular}

Note. 1. Gender; for $r>.04, p<.001$. 